\title{
HYPERPARATHYROIDISM
}

\author{
By Mary G. McGeown, M.D., Ph.D. \\ Medical Urologist, Department of Medicine, Institute of Clinical Science, Belfast, and the Belfast City Hospital \\ and E. Morrison, F.R.C.S. \\ Surgeon, Royal Victoria Hospital, Belfast
}

It was only 32 years ago that Mandl for the first time successfully removed a parathyroid adenoma from a patient. In the intervening years there has been an increasing flow of reports of the successful operative treatment of hyperparathyroidism. Nevertheless, the mode of action of the parathyroid hormone or hormones is still incompletely understood, and the clinical manifestations of the disease are frequently not recognized. It is not a rare disease, and one of us (M.G.McG.) has observed 53 cases since February, I955, while the other (E.M.) has performed parathyroidectomies on 48 of these patients. The remaining five have also had parathyroid adenomata removed (three by T. Kennedy, F.R.C.S., and one each by Professor H. W. Rodgers and M. Bell, F.R.C.S.). These patients have been drawn from the population of Northern Ireland (1.37 million), and we know of two additional patients who have had parathyroid tumours removed during this period of almost four years. This is an incidence of ten cases per million population per annum. These figures make it appear likely that many patients suffering from hyperparathyroidism are not diagnosed, as there is no reason to suppose that the disease is more common in Northern Ireland than elsewhere.

\section{Mode of Action of Parathormone}

There are two main schools of thought concerning the mode of action of parathormone. The earlier view, put forward by Thomson and Collip (1932), and Jaffe (1933), is that the hormone acts directly on bone tissue to cause its dissolution, and that the changes in the body electrolytes are secondary to the bone changes. Albright and Ellsworth (1929) believe that the hormone acts on the electrolyte equilibria of the body, and that the bone changes, when present, are secondary to the chemical changes. These workers think that the primary action is to cause an increase in excretion of phosphate by the kidney, leading to a decrease in the serum phosphorus, which in turn tends to make the body fluids less saturated with regard to the calcium phosphate equilibrium and thus causes withdrawal of calcium phosphate from bone. of The resulting higher serum calcium leads to increased excretion of calcium in the urine, which again causes undersaturation of the body fluids and perpetuates the condition. This theory explains the low serum phosphorus which is characteristic of hyperparathyroidism, which is difficult to explain if the primary action is considered to be the dissolution of bone salt, when both calcium and phosphorus would be poured out $\vec{\theta}$ into the body fluids. However, it has been shown that parathormone causes an increase in the serum calcium and bone changes in nephrector mized animals (Stewart and Bowen, 1951, Talmage and Elliott, 1956). Gaillard (1957) has demonstrated bone resorption and new bone formation when parathyroid glands are cultured in immediate contact with bone tissue explants. An increased excretion of phosphate is not always present in hyperparathyroidism (McGeown, 1957). Neither of the two theories will satisfactorily explain all that is known about the action of parathormone. There is evidence that the administration of parathormone increases the serum citrate (L'Heureux and Roth, 1953; Elliott and Freeman, 1956; Talmage, Elliott and Enders, 1957). Parathormone causes rapid depolymerization of bone mucopolysaccharide, with increase in glycoprotein in the blood and urine (Engel and Catchpole, 1953). Parathormone increases the glomerular filtration rate and the renal plasma $N$ flow (Handler and Cohn, 1952). The volume and N acidity of the gastric juice is diminished and its ్ㅠ peptic activity is increased by parathormone in $\sigma$ dogs (Schiffrin, 1942). In human patients with hyperparathyroidism the volume and acidity of the gastric juice is increased (Clarke, 1959). Recently @ the view has been expressed by Talmage (1956), 0 that parathormone exerts its control on calcium $\overline{0}$ and phosphate metabolism by acting both on bone $\overrightarrow{\mathbb{D}}$ and kidney. Davies and Gordon (r953) have been 
able to separate parathormone into two fractions which affect calcium and phosphate metabolism respectively, by filtration through a cellophane membrane. Our observations on patients support the idea that there is more than one hormone. We have observed a patient who had bone disease with the formation of osteoclastomata for 18 years, and who progressed to renal failure yet never had renal stones; and a second patient who had pathological fractures yet had not formed stones and had normal renal function. On the other hand we know of patients who for periods of up to I 5 years have repeatedly formed stones, but have a normal alkaline phosphatase and no radiological evidence of bone disease. Very high levels of the serum calcium are not usually found in patients who present with renal calculi, even if observed before the onset of renal failure, but are common in patients suffering from bone manifestations. The bone form of hyperparathyroidism is often regarded as a more advanced form of the same disease as that associated with renal calculi, but we do not believe this to be so and consider that there is some essential difference between the different clinical types of the disease.

\section{Clinical Manifestations of Hyperparathyroidism}

Hyperparathyroidism manifests itself by symptoms due to (I) renal calculi or nephrocalcinosis; (2) bone disease; or more rarely (3) hypercalcaemia before symptons of either renal or bone involvement. The early reports of hyperparathyroidism all describe the bone form of the disease, consisting of generalized demineralization of the skeleton, with or without the formation of bone cysts and osteoclastomata. More recent reports all show that the formation of renal calculi is the most common manifestation of the disease. In Marden Black's series of 207 cases (1958), only 12 per cent. had bone disease alone, while 65 per cent. had urinary disease alone. The mode of presentation of our cases is shown in Table $\mathrm{I}$.

None of the patients presenting with renal symptoms had nephrocalcinosis but two of the patients with bone disease also had nephrocalcinosis. Four of the patients who had renal stones
TABLE I

Primary Hyperparathyroidism (53 Cases)

\begin{tabular}{lll|c|c|c}
\hline \multicolumn{3}{c|}{ Presentation } & & Patients & Per Cent. \\
\hline Renal Stone & $\ldots$ & $\ldots$ & $\ldots$ & 48 & 90.6 \\
Bone Disease & $\ldots$ & $\ldots$ & $\ldots$ & 4 & 7.5 \\
$\begin{array}{l}\text { Duodenal ulcer, renal dysfunc- } \\
\text { tion without }\end{array}$ & stones & or & & \\
nephrocalcinosis & $\ldots$ & $\ldots$ & I & 1.9 \\
\hline Total . & $\ldots$ & $\ldots$ & $\ldots$ & 53 & 100.0 \\
\hline
\end{tabular}

had minor radiological bone changes and a slightly elevated serum alkaline phosphatase, but were without bone symptoms.

The true incidence of hyperparathyroidism in patients with renal calculi is not known. Melick and Henneman (1958) found that 9.7 per cent. of 207 consecutive patients attending the Stone Clinic at the Massachusetts General Hospital had hyperparathyroidism. McIntosh, Balfour and Duffy (1958) found hyperparathyroidism in 10 per cent. of $5^{\circ}$ patients with recurrent calculi. Our incidence of 16 per cent ( 48 out of 299 consecutive patients attending a stone clinic) is apparently the highest yet recorded, but we do not think that this figure represents the full incidence of the disease. We think that in at least ten moree patients in this series parathyroid exploration is justified, and the incidence of diagnosis tends to increase as the patients are observed for longer periods. Our patients are to some degree selected in that patients with recurrent calculi are more likely to be referred to a stone clinic. However, in I I patients the diagnosis was made when symptoms due to the first renal calculus occurred (Table 2). It would not be sufficient to limit investigations to patients with recurrent calculi. It is important to make the diagnosis early before irreversible renal damage has occured (Hellström, I950). The risks entailed in exploration of the neck are less than the risk of renal damage if hyperparathryroidism is allowed to continue unchecked, and for this reason operation is sometimes justified in patients with equivocal biochemical changes and rapidly recurring calculi.

Various subsidiary symptoms which were noted are shown in Table 3. Thirst and polyuria were not common symptoms, although emphasized in all

TABLE 2

Stone History of 48 Patients with Hyperparathyroidism

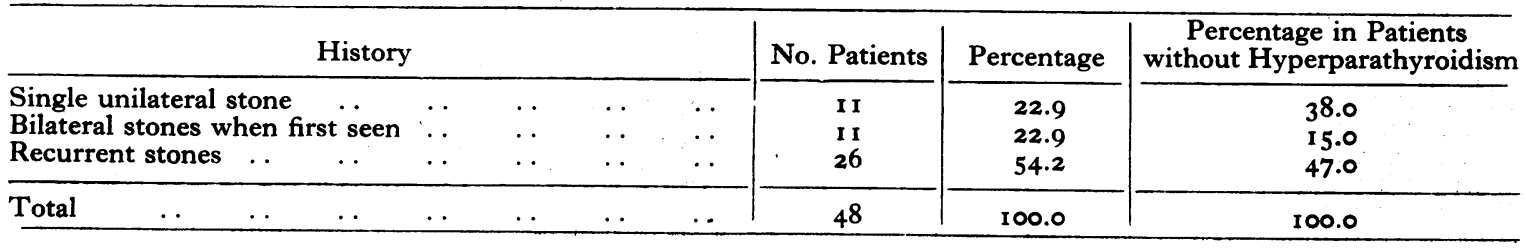

Percentage in Patients

100.0 


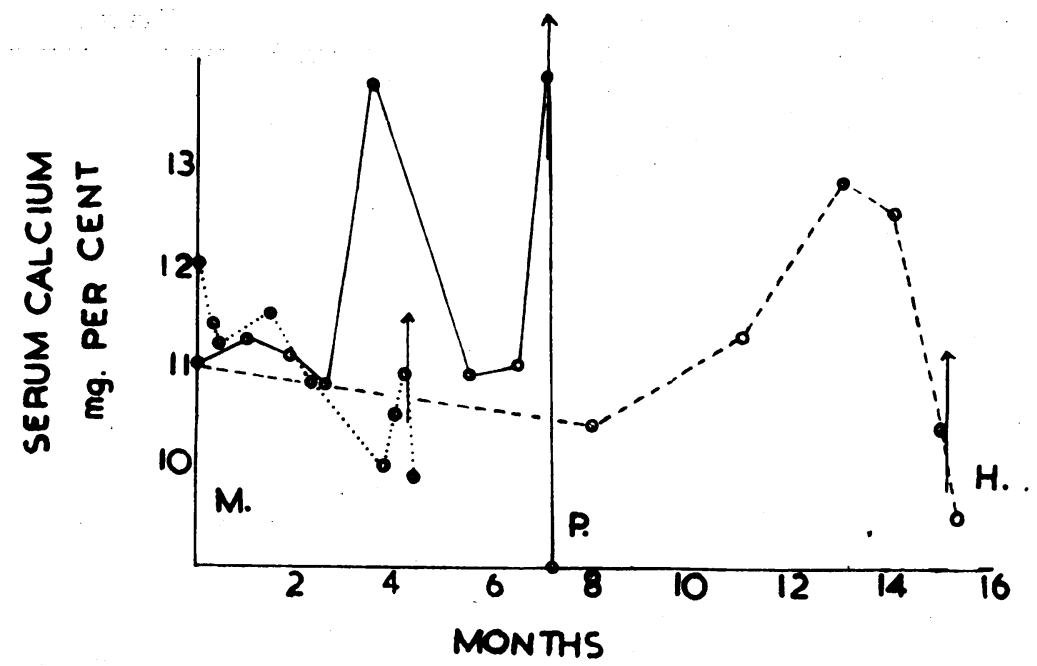

Fig. I.-Examples of fluctuation of the serum calcium in three patients (M., $\mathrm{P}$. and $\mathrm{H}$.). Parathyroidectomy is indicated by the arrow

textbook descriptions of the disease. Only six patients had a urine volume of above two litres and could be considered to have objective polyuria. Gastrointestinal symptoms were relatively common, especially epigastric pain suggestive of duodenal ulcer, and constipation. Some of the patients had duodenal ulcer diagnosed by barium meal but the incidence is not known as this investigation was not carried out as a routine. Even when loss of appetite was not remarkable before operation an increased appetite was frequently experienced in the post-operative period.

The symptoms associated with hypercalcaemia are lassitude and loss of energy, loss of appetite, nausea and vomiting, constipation, although diarrhoea has been observed with very high levels of serum calcium.

Anaemia sometimes occurs in patients suffering from hyperparathyroidism, and is probably

TABLE 3

Subsidiary Symptoms in Patients SufFering From HYPERPARATHYROIDISM

\begin{tabular}{|c|c|c|c|c|}
\hline \multicolumn{4}{|c|}{ Symptom } & \multirow{2}{*}{$\frac{\text { No. Patients }}{3}$} \\
\hline $\begin{array}{l}\text { Thirst and Polyuria } \\
\text { Gastrointestinal: }\end{array}$ & $\cdots$ & $\cdots$ & $\cdots$ & \\
\hline Loss of appetite & $\cdots$ & $\cdots$ & $\cdots$ & 4 \\
\hline Epigastric pain & $\cdots$ & . & $\cdots$ & 17 \\
\hline Nausea and vomitir & & . & . & 3 \\
\hline Constipation . . & . & $\ldots$ & $\cdots$ & almost all \\
\hline $\begin{array}{l}\text { Mental symptoms: } \\
\text { Hallucinations }\end{array}$ & $\ldots$ & & $\ldots$ & 1 \\
\hline Poor orientation in $t$ & ime & d space & . & t \\
\hline Irritability $\quad \ldots$ & . & $\cdots$ & . & 1 \\
\hline Tumour in neck. & $\ldots$ & . & $\ldots$ & 0 \\
\hline
\end{tabular}

secondary to renal dysfunction. Hypertension has been observed in a high percentage of cases by Hellström (1958) and is thought to be due to renal damage. However, some patients with renal damage do not have hypertension and if the patient is over the age of 40 , the hypertension may not be related to the hyperparathyroidism.

\section{Biochemical Aspects}

The biochemical data of these patients will be reported in detail elsewhere and will be considered in general terms here.

The classical changes associated with hyperparathyroidism are: elevation of the serum calcium, low serum phosphorus, increased urinary excretion of calcium and phosphorus, and elevated serum alkaline phosphatase if bone disease is present. The normal values for these vary somewhat in different laboratories; we regard $11.0 \mathrm{mg}$. per cent. the upper limit of the normal serum calcium, and $3.0 \mathrm{mg}$. per cent. the lower limit of normal serum phosphorus although a serum phosphorus as low as $2.5 \mathrm{mg}$. per cent. occasionally has been observed in healthy individuals. The serum calcium is regarded as the most important observation in the diagnosis, and great care is taken to ensure that each individual estimation is reliable. Syringes are washed with distilled water and are dried before use. Blood is withdrawn using stasis only while entering the vein. Estimations are carried out in duplicate in most instances. Estimation of calcium is by overnight precipitation with oxalate, and the precipitate is washed three times before titration with permanganate. The technique of washing has been carefully standardized 


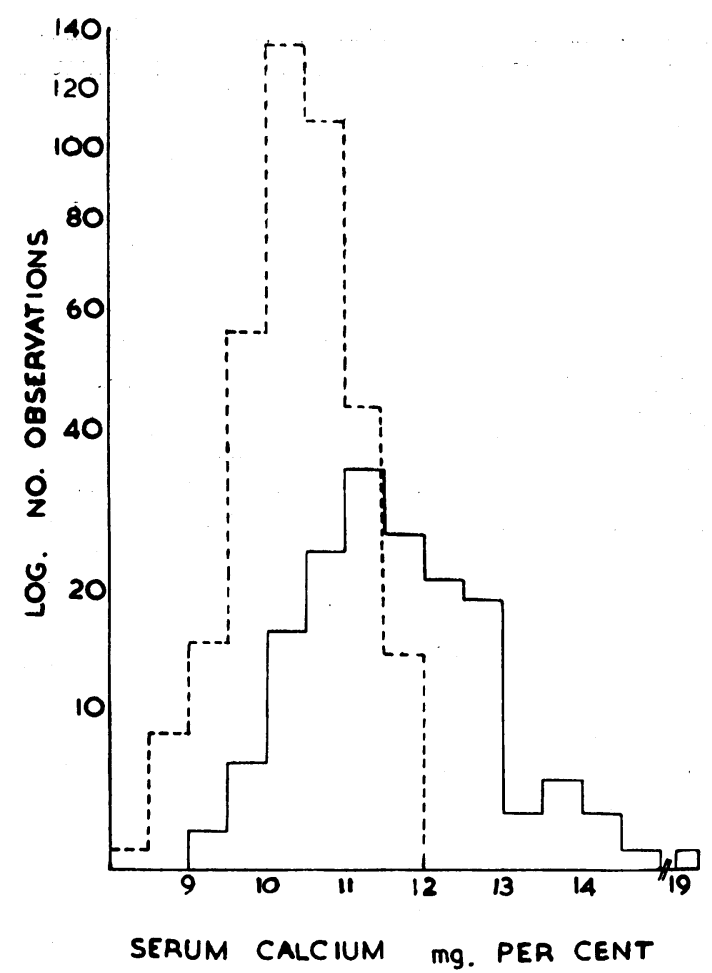

Fig. 2.- 16 I estimations of the serum calcium on 36 patients with hyperparathyroidism (continuous line) compared with 382 estimations on 128 patients without hyperparathyroidism (interrupted line). Note overlap.

to avoid error from this source. It is important that each estimation should be reliable, because in almost all patients who are followed for a sufficiently long period before operation, the serum calcium fluctuates, and values within the normal range occur interspersed with elevated values.
Examples of the fluctuation of the serum calcium in patients with hyperparathyroidism are shown in Fig. I. Parathyroidectomy was carried out at the arrow in each case. If the serum calcium had been carried out once only, the high values could easily have been missed. Fig. 2 shows 16I estimations of the serum calcium on the first $3^{6}$ patients with hyperparathyroidism, compared with 382 estimations on 128 patients with renal stone in whom we do not at present suspect hyperparathyroidism. There is a considerable overlap between the two groups, and values well within the normal range are often observed in patients who are subsequently proved to have hyperparathyroidism. However, only one patient never had a serum of above II.0 mg. per cent., although in 12 patients the highest value was below $12 \mathrm{mg}$. per cent.

The serum phosphorus of patients suffering from hyperparathyroidism also tends to fluctuate over a long period, as shown by examples in Fig. 3 . Low values could easily be missed if the estimation was carried out only once. In Fig. 4, 13 I estimations of the serum phosphorus in the first 36 patients are compared with 292 estimations on 128 stone patients without other evidence of hyperparathyroidism, and shows considerable overlap between the two groups. A normal serum phosphorus frequently occurs in these patients even where renal function is not impaired. It has? been suggested by many workers that a low serum phosphorus (Bogdonoff, Woods, White and Engel, 1956; McIntosh, Balfour and Duffy, 1958) is a better index of hyperparathyroidism than the serum calcium. This has not been our experience, and we have explored three patients with renal stones and persistently low serum phosphorus and without hypercalcaemia, without finding a parathyroid adenoma or evidence of hyperplasia.

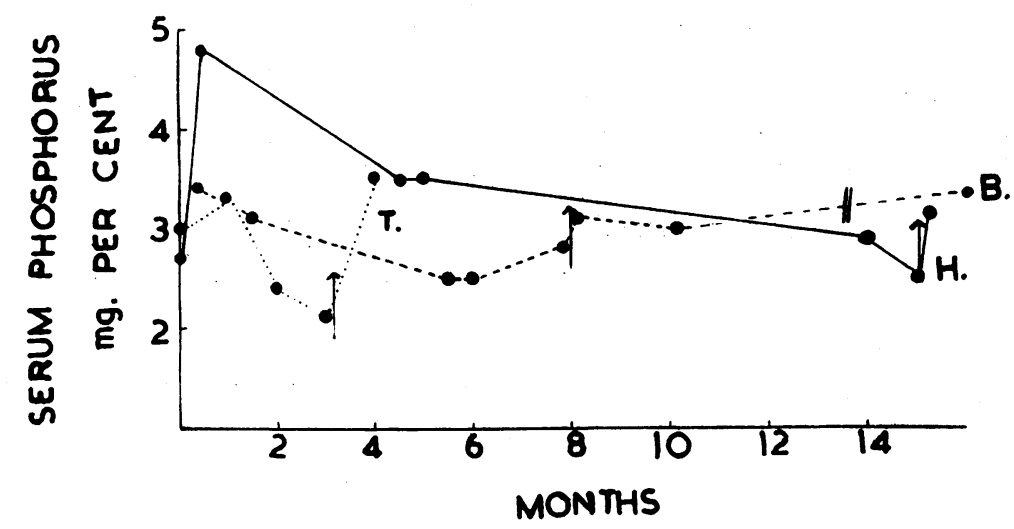

FIG. 3.-Examples of fluctuation of the serum phosphorus in three patients (T., H. and B.). Parathyroidectomy is indicated by the arrow. 


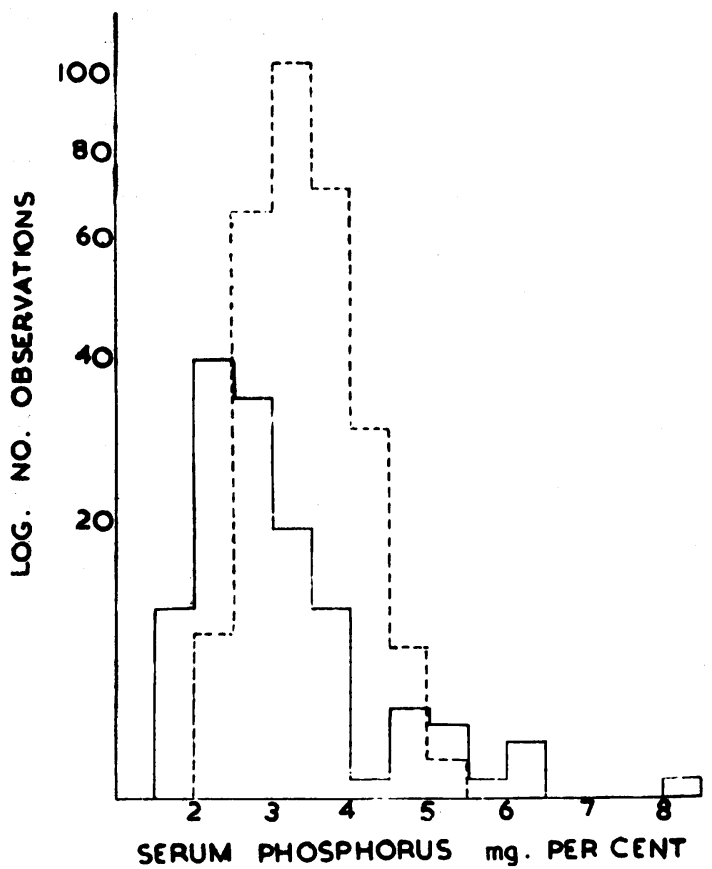

FIG. 4.-131 estimations of the serum phosphorus in 36 patients with hyperparathyroidism (continuous line) compared with 292 estimations on 128 patients without hyperparathyroidism (interrupted line). Note overlap.

The urine excretion of calcium on a standard low intake is estimated for these patients, as previously described (McGeown, 1957). The upper limit of normal excretion under these conditions has been found to be $154 \mathrm{mg}$. per 24 hours. The excretion of the patients with hyperparathyroidism is shown in Table 4 .

It is noteworthy that hypercalcuria is by no means always present in these patients, as it has been frequently stated that its absence almost excludes the condition. The patients with renal stone often have impairment of renal function, and there is an inverse relationship between the blood urea and the urinary excretion of calcium (to be reported elsewhere). Hodgkinson and Pyrah (1958) noted that marked impairment of renal function is associated with a low urinary excretion

TABLE 4

The Urinary Excretion of Calcium in HYPERPARATHYROIDISM

\begin{tabular}{|c|c|c|c|c|c|}
\hline \multicolumn{5}{|c|}{ Urine calcium (mg. per $24 \mathrm{hr}$ ) } & \multirow{2}{*}{$\frac{\text { No. Patients }}{20}$} \\
\hline Below I 54 & $\ldots$ & $\ldots$ & $\cdots$ & $\ldots$ & \\
\hline I 54-200.. & . & $\cdots$ & . & . & 10 \\
\hline Over 200 & $\cdots$ & . & $\ldots$ & $\ldots$ & 23 \\
\hline Total & . & $\cdots$ & . & . & 53 \\
\hline
\end{tabular}

of calcium in hyperparathyroidism. We have twice observed a normal excretion of calcium without impairment of renal function.

The ratio of the urinary clearances of phosphate and creatinine has been used as a measure of the proportion of the filtered phosphate which is unabsorbed by the renal tubules in these patients, and has been reported in detail elsewhere (McGeown, 1957). It is usually elevated in these patients, but occasionally may be normal, and it is frequently elevated in patients with renal stone who have no other biochemical abnormalities suggestive of hyperparathyroidism. For these reasons it has proved to be of little value in arriving at the diagnosis of hyperparathyroidism amongst the patients attending the stone clinic. On the other hand, Kyle, Schaaf and Canary (1958) consider the measurement of phosphate clearance to be a useful diagnostic aid in diseases of the parathyroids.

Intravenous infusion of calcium has been used in the study of parathyroid function by Howard, Hopkins and Connor (1953), Nordin and Fraser (1954) and others. Normal responses in some patients suffering from hyperparathyroidism have been reported by Goldman, Gordan and Chambers (1957). Thomas, Connor and Morgan (1958) have carried out the calcium infusion test in patients with hypercalcaemia from other causes as well as hyperparathyroidism and have found abnormaf responses in all types of hypercalcaemia tested. We have not been impressed with the value of this test in the differential diagnosis of hyperparathyroidism, but we propose to discuss this on a separate occasion.

A phosphate deprivation test has been described by Chambers, Gordan, Goldman and Reifenstein (1956), and it is suggested that it may provoke a definite hypophosphataemia in patients who have previously had normal serum phosphorus values. Our low calcium diet is also low in phosphate, and we have occasionally noted a fall in the serum phosphorus at the end of the diet, but as the serum phosphorus tends to fluctuate in these patients we are not certain of the significance of this observation.

The reports of Fanconi and Rose (1958) and Lloyd and Rose (1958) that in hyperparathyroidism the plasma ionized calcium is elevated out of proportion to the protein-bound calcium affords another test which may be of value in certain patients. Unfortunately the estimation is difficult to perform and requires four hours to carry it out.

\section{The Differential Diagnosis}

The main difficulty in the diagnosis of hyperparathyroidism is due to the fact that any patient with a calcareous renal stone may be suffering 
from hyperparathyroidism. The difficulty is increased by the tendency for both the serum calcium and the serum phosphorus to fluctuate, so that a single normal value by no means excludes hyperparathyroidism. We try to estimate the serum calcium and the serum phosphorus at least four times in each patient, the estimations being repeated at intervals over a period of months. If any abnormality of either is detected, the urinary excretion of calcium is measured and further investigations are made.

Once an elevated value for the serum calcium has been uncovered, other causes of hypercalcaemia must be excluded. Hypophosphataemia may be of help in arriving at the diagnosis of hyperparathyroidism, but it has also frequently been noted in vitamin $\mathrm{D}$ intoxication, multiple myeloma, carcinoma, Hodgkin's disease, sarcoidosis and in the milk alkali syndrome (Thomas, Connor and Morgan, 1958). Electrophonesis of the serum proteins is helpful to exclude multiple myelomatosis and sarcoidosis. Dent (1956) has reported that the hypercalcaemia of hyperparathyroidism is unaffected by cortisone, while it causes a reduction of the serum calcium in vitamin $\mathrm{D}$ intoxication and sarcoidosis. Its effect on the hypercalcaemia of multiple myelomatosis is variable (McGeown and Montgomery, 1956; Thomas, Connor and Morgan, 1958). Milk alkali syndrome may be very difficult to separate from hyperparathyroidism as many of these patients have dyspepsia and a history of large intakes of milk and alkali. The patient who presented with a duodenal ulcer and severe renal dysfunction in Table I was originally considered to have milk alkali syndrome, but at operation was found to have multiple parathyroid adenomata. On the other hand, we have mistakenly explored a patient with milk alkali syndrome, because no biochemical improvement had occurred after several months of a low calcium diet. The possibility of a primary carcinoma elsewhere should be considered in each patient, even if they present with renal stones. Occasionally the presence of Bence-Jones protein in the urine will point to multiple myelomatosis as the diagnosis. Incidentally, while patients with hyperparathyroidism do not usually have marked albuminuria, this may be present on rare occasions. X-ray of the skeleton, especially of the skull, hands and clavicles may reveal early changes even when bone symptoms are absent. The skull has a typical fuzzy appearance, and the lamina dura are absent. The phalanges show a loss of definition of the bone cortex with little erosions, and there are erosions of the terminal tufts of the terminal phalanges (Davies, Dent and Willcox, 1956).

When bone disease is present the diagnosis is usually easy. The level of the serum alkaline phosphatase should be in proportion to the radiological changes. Hyperparathyroidism can simulate the radiological changes of Paget's disease (Law, 1957), and this possibility should be considered when Paget's disease is diagnosed.

\section{Surgical Aspects of Hyperparathyroidism Anatomical Considerations}

The number and location of the parathyroid glands is far more constant than earlier reports on this subject would suggest. The upper pair are usually found at the junction of the upper third and lower two-thirds of the thyroid gland in a plane posterior to the inferior thyroid artery. Enlargement of the superior glands may be missed unless the lateral mass of the thyroid is mobilized and rotated forwards into the neck wound. The lower pair are situated in the loose aerolar tissue around the inferior pole of the thyroid, and may be found several centimetres from it. In about ro per cent. of cases they lie within the upper mediastinum in relation to or within the capsule of the thymus, but easily accessible through the neck wound. With careful dissection, four parathyroid glands can be found in at least 90 per cent. of cases.

The blood supply to these glands comes from the anastomosing channels of the superior and inferior thyroid arteries, and enters the gland in a thin ando often fragile pedicle, which forms the only? anchorage for the gland. The arterial supply branches out under the thin, smooth, glistening capsule. It is easily damaged and the resulting subcapsular haemorrhage makes recognition of the gland impossible. Rough dissection may destroy the fine pedicle and deprive the gland of its blood supply.

\section{Pathology}

One cannot predict clinically whether there will be a single adenoma, multiple adenomata, hyperplasia of all four glands, or carcinoma. The findings in this series of cases are shown in Table 5 .

The recognition of tumour as opposed to hyperplasia may sometimes be difficult. A competent pathologist familiar with the histology of

Table 5

Pathology in 53 Cases of Hyperparathyroidism

\begin{tabular}{|c|c|c|c|c|c|}
\hline \multicolumn{5}{|c|}{ Pathology } & No. Patients \\
\hline \multicolumn{4}{|c|}{$\begin{array}{llll}\text { Adenoma: } & & & \\
\begin{array}{l}\text { Single } \\
\text { Multiple }\end{array} & \ldots & \ldots & \ldots \\
\text { Hyperplasia } & \ldots & \ldots & \ldots \\
\text { Carcinoma } & \ldots & \ldots & \ldots \\
\text { Indefinite but } & \text { good clinical result }\end{array}$} & $\begin{array}{l}\cdots \\
\cdots \\
\cdots \\
\cdots\end{array}$ & $\begin{array}{r}31 \\
6 \\
12 \\
0 \\
4\end{array}$ \\
\hline Total & .. & . & .. & $\ldots$ & 53 \\
\hline
\end{tabular}




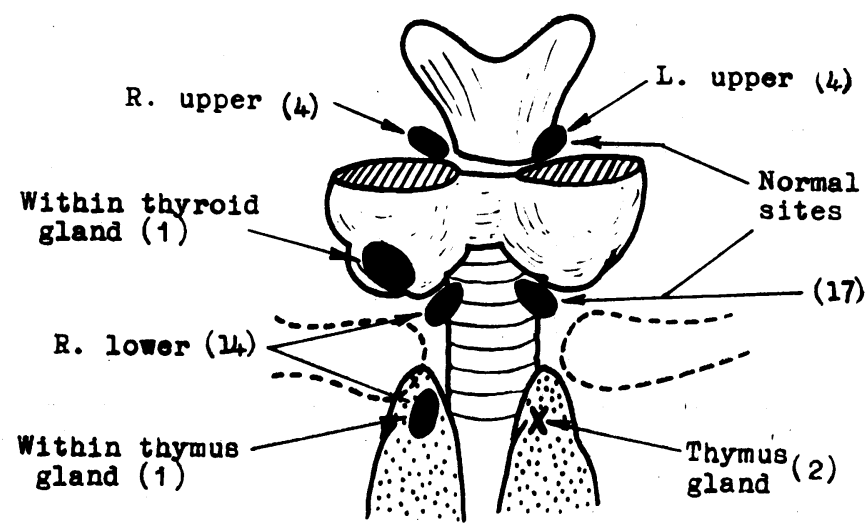

FIG. 5.--Location of parathyroid tumour.

the parathyroid gland should always be available to report on frozen sections of glands or biopsies removed during the operation. The histological distinction between adenoma and hyperplasia may be difficult.

\section{Operative Technique}

An intratracheal anaesthetic is essential as the upper mediastinum may require exploration. Hypotensive drugs help to provide an avascular field, but their use is not essential.

Transverse division of the infrahyoid muscles as recommended by most authors has not been found necessary.

Recognition of the normal parathyroid glands and tumours is not always easy. They are often surrounded by fatty tissue. Hyperactive glands are usually increased in size, although in one of our cases an active tumour was the size of a normal gland. Overactive glands are darker in colour, more vascular, and firmer in consistence than normal glands.

If the cervical exploration fails to reveal a tumour, the dissection is carried into the superior mediastinum, and the upper poles of the thymus are mobilized and resected. We have found three tumours within the capsule of the thymus. The thyroid gland should be carefully inspected, and any suspicious nodule resected. We have found one parathyroid adenoma measuring $3 \mathrm{~cm}$. in diameter completely embedded in the thyroid (Fig. 5).

If the exploration of the neck and upper mediastinum through the neck wound does not reveal the cause of the hyperparathyroidism, the neck wound should be closed, and the patient reassessed after a few weeks before the chest is explored. Sometimes the biochemical abnor- malities disappear, presumably because the blood supply to the offending gland has been destroyed (Table 5).

When a tumour has been found, it is removed and the pathology is confirmed on a frozen section. All the other glands must be identified, as removal of one tumour will fail to cure those cases with multiple tumours, i.e., around ro per cent. When all four glands are hyperplastic, our present policyo is to remove three glands, making sure that one is: left intact.

Convalescence is usually uneventful except in cases with marked skeletal decalcification. In these the ' hungry bones' mop up the circulating calcium and tetany results. The immediate treatment is the slow intravenous administration of 20 per cent. calcium gluconate, repeating the injection every few hours as found necessary. Large doses of vitamin $\mathrm{D}$ or dihydrotachysterol are given, along with effervescent calcium glucono-galactogluconate (Sandoz).

\section{Prognosis}

Much depends on the stage at which the diagnosis is made, and the degree of damage to renal function. In general the prognosis is good when the diagnosis is made early, and where the blood urea is normal or only slightly raised. In patients with bone disease the bone pain rapidly disappears and the bones recalcify, although the cysts remain. We have observed patients with considerable impairment of renal function who have remained well for a period of up to three years after operation. In this type of patient dehydration and electrolyte imbalance may need to be corrected before operation, and even at this stage a good clinical recovery is usually obtained.

From our experience and that of others, it is 
clear that the spectrum of parathyroid activity grades upward from the normal to the obviously hyperfunctioning glands, with no clearcut line of demarcation between them. The operative findings in patients who have clinical and biochemical evidence of hyperactivity vary from gross enlargement of a single gland, or of multiple glands, to glands of normal size, or even smaller than normal (Black and Zimmer, 1956). Hyperparathyroidism thus appears to be comparable with thyrotoxicosis and Cushing's syndrome (Montgomery, 1958). While there is considerable evidence that this is the proper view to take of hyperparathyroidism, in a series of patients with renal calculi it can give rise to difficulty in excluding the possibility of hyperparathyroidism in individual patients. The estimation of the ionized calcium may prove to be of value, but unfortunately it is not suitable for use in large numbers of patients. We feel that many cases of hyperparathyroidism remain undiagnosed simply because the total serum calcium is not estimated frequently enough in patients who suffer from renal stone, and that many more cases could be discovered even without the more difficult estimation of the ionized calcium.

\section{Acknowledgments}

M.G.McG. wishes to acknowledge that the earlier part of this work was carried out under a personal grant from the Medical Research Council, and later with the aid of a clinical research fellowship given by the Royal Victoria Hospital.

We are grateful to the numerous surgeons who have referred patients and to Miss Eileen Martin and Mr. D. Neill for help with the biochemical estimations.

\section{BIBLIOGRAPHY}

ALBRIGHT, F., and ELLSWOR'TH, R. J. (r929), f. clin. Invest., 7, 183.

BLACK, B. MARDEN, and ZIMMER, J. F. (1956), Arch. Surg. (Chicago), 72, 830 .
BOGDONOFF, M. D., WOODS, A. H., WHITE, J. E., and ENGEL, F. L. (1956), Amer. F. Med., 21, 583 .

CHAMBERS, 'E. L., GORDAN, G. S., GOLDMAN, L., and REIFENSTEIN, E. C. Jr. (1956), $\mathscr{f}$. Clin. Endocr., 16, 1507. CLARKE, S. D. (1959), Personal communication.

DAVIES, B. M. A., and GORDON, A. H. (1953); Nature (Lond.), I7I, I, I 22.

DAVIES, D. R., DENT, C. E., and WILLCOX, A. (1956), Brit. med. $\mathcal{F}$., ii, 5,002 .

DENT, C. E. (1956), Ibid., i, 230.

ELLIOTT, J. R., and FREEMAN, S. (1956), Endocrinology, 59, 181 .

ENGEL, M. B., and CATCHPOLE, H. R. (1953), Proc. Soc. exp. Biol. (N.Y.), 84, 336.

FANCONI, A., and ROSE, G. A. (1958), Quart. F. Med., 27, 463.

GAILLARD, P. J. (1957), Schweiz. med. Wschr., 14, 447.

GOLDMAN, J., GORDAN, G. S., and CHAMBERS, E. L., Jr. (1957), Ann. Surg., 146, 407.

HANDLER, P., and COHN, D. V. (1952), Amer. F. Physiol., 169,188 .

HELLSTRÖM, J. (1950), Acta chir. scand., 100, 391.

HELLSTROM, J., BIRKE, G., and EDVALL, C. A. (1958), Brit. F. Urol., 30, 13.

HODGKINSON, A., and PYRAH, L. N. (1958), Brit. $\mathscr{f}$. Surg,. 46, 10.

HOWARD, J. E., HOPKINS, T. R., and CONNOR, T. B. (I953), F. clin. Endocr., $13, \mathrm{I}$.

JAFFE, H. L. (1933), Arch. Path. (Chicago), 16, 63 and 236.

KYLE, L. H., SCHAAF, M., and CANARY, J. J. (1958), Amer. F. Med., 24, 240.

LAW, W. B. (1957), Med. F. Aust., 2, 455.

L'HEUREUX, M. V., and ROTH, G. J. (1953), Proc. Soc. exp. Biol. (N.Y.), 84, 7.

LLOYD, H. M., and ROSE, G. A. (1958), Lancet, ii, 1,258.

McGEOWN, M. G. (1957), Clin. Sci., 16, 297.

McGEOWN, M. G., and MONTGOMERY, D. A. D. (1956), Brit. med. Э., i, 86.

McINTOSH, H. W., BALFOUR, J. A., and DUFFY, M. H (1958), Brit. F. Urol., 30, 292.

MELICK, R. A., and HENNEMAN, P. H. (1958), New Engl. $f_{0}$ Med., 259, 307.

MONTGOMERY, D. A. D. (1958), Personal communication.

MUNSON, P. L. (1955), Ann. N.Y. Acad. Sci., 60, 776.

NORDIN, B. E. C., and FRASER, R. (1954), Clin. Sci., 13, 477.

SCHIFFRIN, M. J. (1942), Amer. F. Physiol., 135, 660.

STEWART, G. S., and BOWEN, H. F. (1951), Endocrinology, 48, 568.

TALMAGE, R. V. (1956), Ann. N.Y. Acad. Sci., 64, 326.

TALMAGE, R. V., and ELLIOTT, J. R. (1956), Endocrinology, $59,27$.

TALMAGE, R. V., ELLIOTT, J. R., and ENDERS, A. C. (1957), Endocrinology, 6I, 256.

THOMAS, W. C., CONNOR, T. B., and MORGAN, H. G. (1958), 7. Lab. clin. Med., 52, $1 \mathrm{I}$.

'IHOMSON, D. L., and COLLIP, J. B. (1932), 'The Parathyroid Glands,' Physiol. Rer., 12, 209.

\section{RUTHIN CASTLE, NORTH WALES}

A Clinic for the diagnosis and treatment of Internal Diseases (except Mental or Infectious Diseases). The Clinic is provided with a staff of doctors, nurses, technicians, modern Radiological and Physiotherapy departments.

The surroundings are bsautiful. The climate is mild. There is central heating throughout. The annual rainfall is $\mathbf{3 0 . 5}$ inches, that is less than the average for England.

The Fees are inclusive and vary according to the room occupied.

For particulars apply to THE SECRETARY, Ruthin Castle, North Wales. 